\title{
The State of Massive Open Online Courses (MOOCs) in Engineering Educa- tion: Where do we go from here?
}

\section{Dr. Flora S Tsai, Singapore University of Technology and Design}

Dr. Flora Tsai is a lecturer at Singapore University of Technology and Design (SUTD) and an associate lecturer at Singapore Institute of Management (UniSIM). She has over eleven years of teaching experience for undergraduate software engineering subjects. She was a graduate of MIT, Columbia University, and NTU. Dr Tsai's current research focuses on developing intelligent techniques for data mining in text and social media. Her recent awards include the 2005 IBM Faculty Award, 2007 IBM Real-time Innovation Award, 2010 IBM Faculty Innovation Award, and 2012 Smarter Communications Innovation Award. She has also received honorable mention for her article entitled "Engineering the Future of Education" in the Future Technology Predictions Competition organized by the Proceedings of the IEEE. She has published more than 60 refereed journal and conference papers. She is currently a senior member of both IEEE and ACM.

Mr. Kyle H Wong, Singapore American School 


\title{
The State of Massive Open Online Courses (MOOCs) in Engineering Education: Where do we go from here?
}

\begin{abstract}
The proliferation of massive open online courses (MOOC) is dramatically changing the way we teach and learn. These online courses have the flexibility to combine social networking with online videos and homework, allowing participants to learn at their own pace. Furthermore, unlike conventional classes, they can potentially reach an unlimited number of students worldwide. Examples of MOOCs that have been established recently include Coursera, Udacity, edX, MITx, and Khan Academy. These courses continue in the collaborative spirit of open sharing of software and information brought on by the open source and Wikipedia movements. In addition, the courses help to bridge the gap between the rich and poor within the digital divide.

The rapid growth and popularity of the MOOCs have led experts to predict that the traditional higher education market will face pressure over the next several years, due to growing competition from MOOCs as well as international universities. Although the top educational institutions will continue to attract students, other institutes are likely to suffer if they do not integrate MOOCs and new technologies in their curriculum, especially given the rapidly changing learning preferences in the current generation of students.

Since no open education standard has emerged to define the future of MOOCs, there is currently a barrage of unregulated courses on the Web that could potentially lead to misinformation conveyed to the online learners. This paper reviews and compares the current platforms and technologies available in the online engineering education arena, proposes a model for combining MOOCs with live university courses, lays the groundwork for open standards for engineering education, summarizes the international challenges ahead, and discusses the implications for future educators and students. The impact of this study will help educators manage the vast content in order to integrate online education in their own curriculum, and provide guidelines on how to best utilize the MOOCs in the future.
\end{abstract}




\section{Introduction}

The open source paradigm of massive information sharing has spurred many opportunities for education. Massive open online courses (MOOC), which are freely available courses that combine social networking with online videos and assessment, will grow in the coming years to reach learners of all ages. Unlike conventional classes, MOOCs can potentially reach an unlimited number of students worldwide. MOOCs have the advantages of engaging learners who participate according to predefined learning goals, prior knowledge and skills, and common interests (McAuley, 2010). Although they share some similarities to traditional courses, such as preset syllabus, timeline, homework, and exams, MOOCs are usually zero or low cost, require no physical attendance, and offer no formal degrees (only completion certificates).

MOOCs are not new, and were referred to in the past as open courseware, but were typically unstructured and unscheduled courses. In 2007, there were over 3000 open courseware courses available from over 300 universities worldwide, in repositories such as MERLOT, Connexions, OpenLearn and others, with hundreds of thousands of pieces of content representing thousands of freely available learning hours (Hylen, 2007).

Many factors have helped propel MOOCs to the center of the education stage, including fast Internet connections and the rising costs of conventional universities. Although free online courses have existed for decades, they usually consists of individual instructors posting their recorded explanations online. The past year has seen hundreds of thousands of motivated students around the world embrace MOOCs as a path toward advanced skills and high-paying jobs, without paying tuition or collecting a college degree. Many of these courses come with an informal credential (but not necessarily free). Since no open education standard has emerged to define the future of MOOCs, there are large numbers of unregulated courses on the Web that could potentially lead to misinformation conveyed to the online learners.

MOOCs have been predicted to possibly threaten the livelihood of for-profit institutions and smaller, regional colleges and universities, according to a report by Moody's Investor Service (Lewin, 2012a). These for-profit education companies and smaller not-for-profit colleges may be left out of emerging high reputation online course networks. However, the continued growth of conventional online programs can benefit the credit ratings of brand-name and niche institutions, especially if the well-reputed institutions band together around online offerings to reduce operating costs (Martin, 2012). On the other hand, if the reputable institutions rush too carelessly into MOOCs, they could end up reducing their educational stronghold by diluting their brand. Thus, it is important for universities to plan carefully their long-term goals in entering the the MOOC movement, and control the quality of the courses being posted (Lewin, 2012b).

This paper is organized as follows: Section 2 reviews and compares the current platforms and technologies available in the online engineering education arena, Section 3 proposes a model for combining MOOCs with live university courses, 
Section 4 lays the groundwork for open standards for engineering education, Section 5 summarizes the international challenges ahead, Section 6 discusses the implications for future educators and students, and Section 7 concludes the paper.

\section{Review of MOOCs}

This section reviews the current offerings in the MOOC market, such as Khan Academy, Coursera, edX, MITx, and Udacity.

Khan Academy (www.khanacademy.com) was one of the first online courses available on a massive scale, which began in 2004 when Salman Khan tried to teach math remotely to his elementary school cousins. Instead of repeating his tutorials to each student, he recorded short videos with explanations and placed them on the Internet, adding automatically graded exercises. Currently more than 3600 videos have been watched more than 700 million times. The Khan Academy videos are not scheduled courses, but rather online videos that are available to anyone on a variety of topics ranging from mathematics to history, healthcare and medicine, finance, physics, chemistry, biology, astronomy, economics, cosmology, organic chemistry, American civics, art history, macroeconomics, microeconomics, and computer science.

The videos are usually catered for pre-university students, although advanced videos on calculus and other university-level courses are also available. There are no advanced social networking capabilities other than posting comments on the video link itself. Not all of the videos have online exercises linked to them, and there could be some errors in the videos themselves, which are sometimes annotated with corrections. There are no certificates offered, although there are "energy points" that are given to spur students' motivation in completing videos and assignments. Figure 1 shows a screenshot of the Khan Academy online assignment for calculus. One of the advantages of the videos is that they are short and self-contained, with duration often not exceeding 10 minutes in length. However, more complex topics require several videos to complete the topic, so many videos may be labeled with parts (Part 1, 2, etc.). Although the target audience appears to be pre-university students, the videos have been assigned to university-level remedial calculus students at the Singapore University of Technology and Design, both for reviewing background math topics, and as an additional resource for current calculus topics. Instructors who wish to monitor the progress of students can ask students to add their email as a coach. Thereafter, the instructors can check the progress of their students in the videos and assignments they complete if the students log in to their account. 


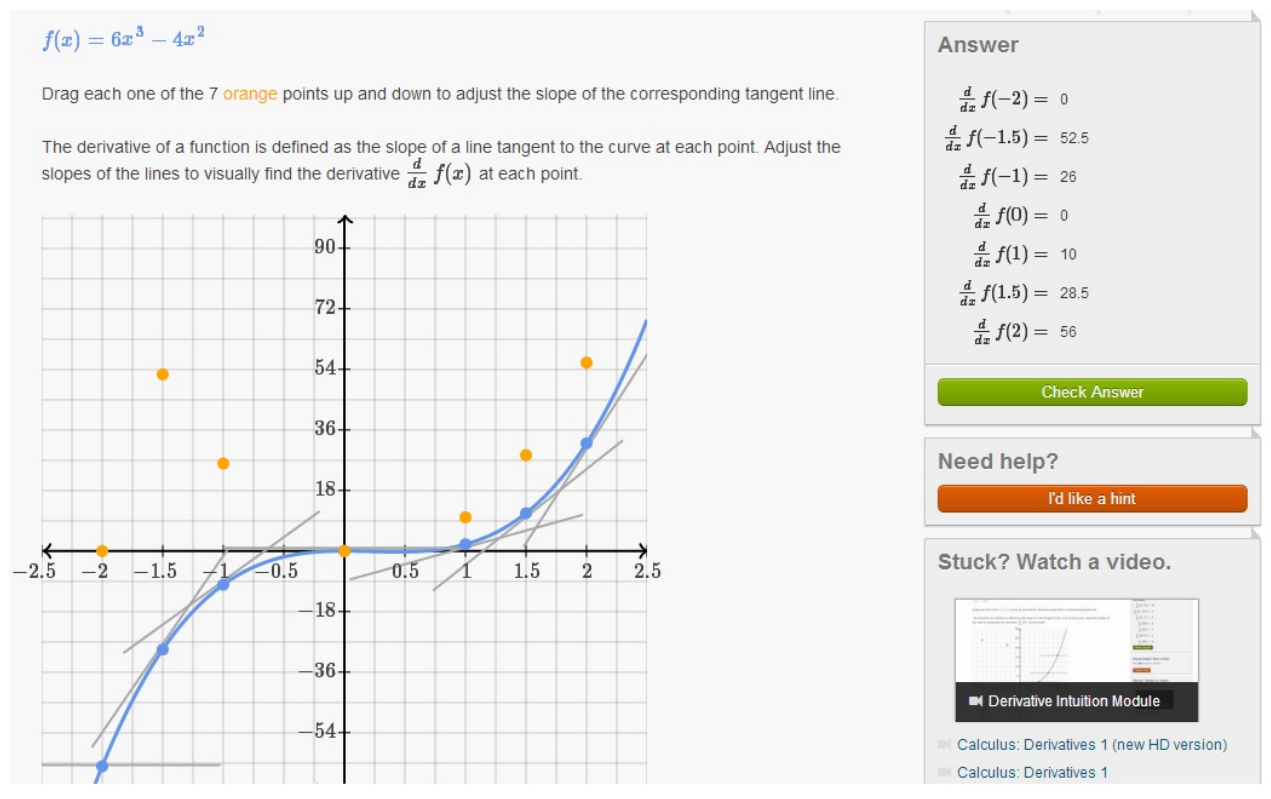

Figure 1. Example of a calculus question on Khan Academy.

Another school where Khan Academy is widely used is in the mathematics classes at Singapore American School (SAS), which has students from kindergarten to high school. Khan Academy is used at SAS as both a supplement and tool of learning. The teachers assign a lesson on Khan Academy as homework to students. Each Khan Academy lesson has a set of exercises to go with it, and completing the exercises requires a student to watch the assigned Khan Academy video, as the problems closely relate to the ones given in the video. Also, due to the 'energy point' system, it is almost inevitable that students will go to other lessons and do exercises there. The energy point system is rankable, thus classmates will want to be 'better' than their peers, and hence Khan Academy serves a supplemental purpose to learning as well. Khan Academy videos are not recommended for people experienced with the subject at hand, as Khan gives the basics only. However, if students wish to refresh their skills, Khan Academy is a great place to go to, due to its exercises and videos. Khan Academy is a great place to learn, as Khan rewards you for learning more. A small improvement would be the 'review' system- after a student has completed a set of exercises, after a while, Khan Academy marks the exercise as needing review. Students have to go through the entire set of exercises again to get rid of the review marker.

Another MOOC which is rapidly gaining traction in their course offerings and partner institutions is Coursera (www.coursera.org). Coursera is a for-profit educational technology company founded by computer science professors Andrew Ng and Daphne Koller from Stanford University. Coursera partners with various universities and makes some of their courses available online free for a large audience (Kolowich, 2012). As of November 2012 almost 2 million students from almost 200 countries have enrolled in at least one course. However, only hundreds of thousands of students have actually completed the courses and 
received certificates, since completion rates are less than $10 \%$, according to Daphne Koller in an interview with Knowledge@Wharton (Koller, 2011).

We describe firsthand experiences in two recent courses offered by Coursera, Learn to Program: The Fundamentals (Python) and Social Networking Analysis. The Python course was held from Sep 24th 2012 with a total duration of 7 weeks, with an estimated workload of 6-8 hours/week. This course provided an introduction to computer programming using Python. Topics include elementary data types (numeric types, strings, lists, tuples, dictionaries and files), control flow (if, for, while), functions, modules, objects, methods, fields and mutability. This course assumed no particular background, and the format consisted of 1 to 2 hours of lecture each week, which are made up of videos that are generally shorter than 10 minutes each. Each video contained integrated quiz questions. There were also weekly standalone exercises that are not part of the video lectures and a (nonoptional) final exam. Students who successfully complete the class with a final grade of at least $70 \%$ received a certificate signed by the instructor. This course can be taken by people completely new to programming, and is intended to be self-contained.

The Social Network Analysis (SNA) course started on Sep 24th 2012 with a duration of 8 weeks and an estimated workload of 5-7 hours/week (8-10 if completing additional programming exercises). This interdisciplinary course uses social network analysis to understand how networks form, how they are structured, and how this structure influences processes occurring over networks. There were no math or programming prerequisites for the class. However, prior programming knowledge is assumed for students who opted for the optional programming exercises in $\mathrm{R}$ statistical programming language along with NetLogo. The class consisted of lecture videos, which are between 8 and 12 minutes in length, and 1-2 integrated quiz questions per video. There were also standalone homeworks that were not part of video lectures, optional programming assignments, and a (not optional) final exam. Students who successfully complete the class with a final grade of at least $80 \%$ received a certificate signed by the instructor.

For the SNA course, 61,285 students registered, 25,151 watched at least one video, 15,391 tried at least one in-video quiz, 6,919 submitted at least one assignment, 2,417 took the final exam. 1303 earned the regular certificate (a completion rate of $2.1 \%$ ). Of the 145 students submitting a final project, 107 earned the programming (i.e. 'with distinction') version of the certificate.

There was a note the Coursera certificate, which stated that the online offering of this class does not reflect the entire curriculum offered to students enrolled at the University. This statement does not affirm that this student was enrolled as a student at the University in any way. It does not confer a grade, credit, or degree, and it does not verify the identity of the student.

As Coursera courses are self-enrolling and often require no prerequisites, it could be possible that students are not matched to the level of the course (such as being too easy or difficult). Thus, it may be advantageous to conduct a pre-screening 
survey or test to match a student to the appropriate course for their background level and knowledge. One of the constraints of the Coursera course is that it follows a pre-defined schedule, and cannot be taken after the completion date of the course. Thus, there is no flexibility in allowing a student to take a course whenever they wish and view the course archives after a scheduled course has completed, which may be a viable option since many SNA course participants mentioned a prior course called Networked Life, whose archives were not available for those who did not previously register for the course.

In terms of course content and videos, it is often possible to complete the homework and assignments without watching the videos and just reading the course notes. Sometimes the homework questions do not test on knowledge conveyed in the videos or course notes, but rather on reporting the results of running a program or simulation. Thus, more planning should be done in setting assessment questions that are better able to meet the overall course objectives. Unlike traditional classes, the homework and assignments can be submitted multiple times (sometimes up to 100 times), making it possible to score well without actually learning or understanding the answers to the questions. In the multiple attempts allowed, the grade entered into the system is the highest grade out of all the attempts. Thus, it is possible to get almost $100 \%$ after only a few attempts as immediate feedback and hints are given on the questions after submitting the homework. Furthermore, the lowest grade out of all the homeworks submitted will not be counted towards the final grade, and it is also possible to submit homeworks and assignments after the due date by applying for late days. The grade required to receive a Coursera certificate was not consistent, as it was $70 \%$ in one course and $80 \%$ in another. Moreover, as noted in the final certificate, Coursera does not verify the identity of a student, which may be a big problem when using the certificates in practice.

Udacity (www.udacity.com) is another online education venture by former Stanford Professor Sebastian Thrun. Udacity was started after Thrun taught an open course on Artificial Intelligence course with Peter Norvig, a Google colleague. The course attracted 160,000 students in 190 countries and an additional 200 registered for the course on campus. After a few weeks, attendance at Stanford dropped to about 30, as students gravitated towards the online videos. The MOOCs included virtual office hours and online discussion forums where students could ask and answer questions, and vote on which were important enough to filter up the professor. Since Udacity opened registration on Jan. 23, 2012, more than 90,000 students have enrolled in the courses. Udacity courses are designed and produced in-house or with companies like Microsoft and Google (Pappano, 2012). Many students were attracted to the always-available, always-replayable and free nature of this style of learning that can help to elevate knowledge for everyone around the world.

On Feb. 13, 2012, the Massachusetts Institute of Technology, which has been posting course materials online for 10 years, opened registration for its first MOOC, a circuits and electronics course. The course served as the prototype for its MITx project, which will eventually offer a wide range of courses and some 
sort of credential for those who complete them. MITx builds on the Institute's decade-old OpenCourseWare (OCW) initiative, which put MIT course materials such as lecture notes and lecture videos online (Hardesty, 2012). OCW actually helped the MIT brand, as shown in a 2010 survey, where 57 percent of MIT undergrads reported that they had been aware of OCW before applying to MIT, and of those, 31 percent said that OCW had a "significant" or "very significant" influence on their decision to attend (Hardesty, 2012). A separate faculty survey found that 34 percent of faculty who had posted material on OCW felt the site had improved their professional standing (Hardesty, 2012).

EdX (www.edx.org) is another MOOC, which is a not-for-profit online education initiative by MIT, Harvard, and the University of California, Berkeley which offers online university-level courses in a wide range of disciplines to a worldwide audience at no charge. The learning platform is developed as opensource software and made available to other institutions that want to make similar offerings that moves beyond videos of lectures to interactive experience (edX, 2013). Certificates of successful completion will be offered but students cannot receive college credit (edX, 2013). We have recently enrolled for a Python course in edX entitled 6.00x Introduction to Computer Science and Programming, which is a 17-week course from Feb. 4, 2013 until June 3, 2013. This course is an introduction to using computation to solve real problems, aimed at students with little or no prior programming experience who have a desire to understand computational approaches to problem solving. Although the pre-requisites are similar to the Coursera Python course reviewed earlier, the edX course has a higher difficulty level, especially for the weekly problem sets, which require writing Python programs. Some of the problem sets involve engineering examples, such as approximating the total radiation exposure from a radioactive decay curve. In this problem, students are asked to find the amount of radiation a person is exposed to during some period of time by completing a Python function called "radiationExposure" with inputs start time, stop time, and step size (the width of the estimation rectangle). Another engineering example is to write a program to encrypt plaintext into ciphertext using the Caesar cipher.

Table 1 shows a summary of the MOOCs reviewed in this section, with date founded, number of courses/videos, partner institutions. Some of the MOOCs do not have university partners, but rather partner with individual professors for courses. However, based on the growth of the MOOC startups in the past year alone, the market may be geared towards consolidation in the near future, especially if open standards can be adopted for online education. 
Table 1. Summary of MOOCs.

\begin{tabular}{|c|c|c|c|c|}
\hline MOOC & $\begin{array}{c}\text { Date } \\
\text { Founded }\end{array}$ & $\begin{array}{c}\text { \#Courses/ } \\
\text { Videos }\end{array}$ & $\begin{array}{c}\text { \#Students } \\
\text { (millions) }\end{array}$ & \#Partners \\
\hline Coursera & 2012 & $\begin{array}{c}328 \\
\text { courses }\end{array}$ & 3 & 62 \\
\hline Khan Academy & 2006 & $\begin{array}{c}4000 \\
\text { videos }\end{array}$ & 10 & - \\
\hline Udacity & 2012 & $\begin{array}{c}22 \\
\text { courses }\end{array}$ & 0.7 & - \\
\hline MITx / OCW & 2002 & $\begin{array}{c}2100 \\
\text { courses }\end{array}$ & 100 & - \\
\hline edX & 2012 & $\begin{array}{c}20 \\
\text { courses }\end{array}$ & 0.5 & 20 \\
\hline
\end{tabular}

Compared to Coursera, Khan Academy videos are not distinctly organized into courses, which could be good if an instructor prefers to assign individual videos and topics to supplement their live courses. However, Khan Academy could benefit in the future if they offer a suggested list videos to watch for a given course, such as freshmen calculus. Assessment of questions are very important in online courses, and the type of questions should be indicative of the learning objectives. In addition, additional problems include monitoring quality and certifying that a specific student is taking a course. Such issues need to be resolved in order to maintain the reputation of the degree and the high level of integrity demanded by industry and society (Tabas, LeMay, and Freije, 2012).

Although educational institutions should play a leadership role in creating the best online education possible, the rapid growth of MOOCs and university partnerships in MOOC networks leads many professors to wonder what MOOC's mean for the future of their university.

\section{Model for Live University Courses}

With the growth of MOOCs, many instructors may feel that their jobs will be threatened in the future. A report released by Moody's Investors Service predicted that the new open online courses could adversely affect the business of conventional online higher education(Jaschik, 2012). Many faculty members at universities which signed up for MOOC networks such as Coursera had no knowledge or input in the negotiations that took place while they were away during the summer months. Professors are cautious about signing up with MOOCs and question what it could mean for the future of their university. Many 
faculty are unclear about how joining the MOOC networks can be valuable, and some see it as diminishing the quality standard of their courses. Others argue that online education cannot teach creative problem-solving and critical-thinking skills.

Although it is true that the traditional role of a lecturer conveying passive information may eventually be replaced by a more dynamic model, live instructors will still be critical in the future of education. With the integration of MOOCs into live classrooms, traditional schools will still play a vital part in creating content, assigning questions, defining the syllabus, awarding degrees and diplomas, interacting with students, and providing feedback. Schools should focus on their advantages over MOOCs, such as personal active feedback to the students, live interaction and discussions, in-class assessments, and live audience feedback from the students to the instructor.

Institutions which embrace MOOCs will benefit the most out of the new educational developments. Traditional instructors will still be required in the future, but their roles will adapt and change with time, with less focus on lecturing and passive delivery of knowledge, and more on providing innovations and spurring motivation and creativity, gauging and customizing levels. Most universities will move towards blended model that combines in-class learning with online courses. The current university model can only survive in the future if advanced resources for classroom customization are adopted. As the classroom adoption of online technologies spreads, technologies will be used to create the future interactive learning, teaching, and assessment tools. Schools across all levels can customize the difficulty levels according to individuals or entire classes. Active and interactive learning approaches can be adopted and customized, and classroom time can focus on problem-solving activities that achieve deeper understanding and foster creativity (Tsai et al., 2012, 2013). Pedagogical advances such as SCALE-UP (Student-Centered Activities for Large Enrollment for Undergraduate Programs) (Gaffney et al., 2008) or applying hardware- and software-based educational implements that offer learning experiences for individuals with various learning preferences and accommodate a diversified number of teaching methods and engineering topics (Riojas et al., 2012).

This blended model, sometimes called the flipped classroom, teachers have time to interact with students, motivate them and challenge them. Stanford University has adopted this blended model, with considerably higher attendance than in many standard lecture-based classes (Koller, 2011). In addition, a California school district used the Khan Academy for a remedial math class, seventh graders sharply improved their performance, with a 78\% increase in students reaching advanced or proficient levels (Koller, 2011). Another study concluded that both students and faculty believe that technical topics can be effectively taught via online methods and online courses are seen as effective as face-to-face courses, which is a significant result in favor of online engineering education (Kinney and Liu, 2012). 
A 2010 Department of Education analysis, based on 45 studies, showed that online learning is as effective as face-to-face learning, and that blended learning is considerably more effective than either (Koller, 2011). Thus, blended learning can mean better outcomes at the same or lower cost. Universities can be strengthened with the integration of online courses, and schools should explore ways in which the technologies can make on-campus, in-person education even better. Online technologies excel at teaching content, and the residential campus model can teach the skills one learns through human interaction, such as how to compromise, inspire, persuade; how to build a life of high ethics and moral value; how to work creatively with people of different backgrounds; when, and how, to speak - and when, and how, to listen. The university of the future should offer the best of both worlds, integrating the best ways to learn online with the best ways to learn in person (Reif, 2012). Schools should blend new educational delivery methods with their traditional, hands-on model to make residential education even more effective. Ideally, by adopting the new technologies to help improve education, the cost of residential education can be lowered while simultaneously improving its quality (Reif, 2012).

Universities and colleges should act and join the MOOC movement sooner rather than later because of the risk involved in doing nothing when developments are so rapid. From the perspective of individual researchers and educators, publishing teaching materials openly offers a number of positive outcomes, although restrictions imposed by copyright law and the lack in many institutions of a reward system that fosters the development and use of MOOCs remain important inhibitors (Hylen, 2007).

Those who shun the new technologies may end up losing the most from the new wave in education. Smaller colleges that are unable to join emerging networks or carve out an independent niche may be impacted by declining student demand.

Thus, the best model is to embrace the new technologies and integrate MOOCs in existing courses, adding value in live personal interactions with students. The world still expects renowned institutions to incubate brilliant young talent, creating the innovations that fuel our society.

\section{Open Standards}

With the rapid proliferation of online courses, open standards are required to integrate and index online courses, provide repositories for education content, and transcribe text for online courses. Once open educational standards are defined, systems can be programmed to take bits and pieces of learning objects and content into a unified platform. The learning content at issue is the open educational material organized as courses as well as smaller chunks of learning, often referred to as learning objects. The content involves websites, simulations, text, images, sound or videos in digital format.

Until there is an open education standard, we need to deal with many type of educational platforms, such as Khan Academy, Coursera, various universities' open courseware, online material and text from books. Open educational resources (OER) such as those provided by MOOCs refer to accumulated digital 
assets that can be adjusted and which provide benefits without restricting the possibilities for others to enjoy them (Hylen, 2007).

One challenge facing the OER movement is the rapidly growing number of learning materials and repositories leading to the need for effective search and discovery tools. Items of interest to a teacher may not be part of library catalogues, public databases or online journal subscriptions. Although there are technical solutions to this problem, such as attaching metadata (data about data or descriptive information about materials) to the resources to make them easier to find for harvesting machines utilized by users via search interfaces, but adding metadata to a resource is time-consuming and faces the problem that the person adding metadata does not know the circumstances under which people will use the resource (Hylen, 2007). Thus, it is important that third party organizations step in to define open standards for education search and retrieval of online content.

One example of an open standard is the IEEE Standard for Smart Networked Learning Objects, currently under development. This standard defines methods for storing and retrieving learning objects for remote laboratories, such as interfaces for devices connected to user computers over computers networks and the devices themselves (Saliah-Hassane, 2012). They are also learning scenarios for communications necessary to conduct an activity of practical online laboratory work; to design and implement mechanisms that make smart learning environment formed by the ad hoc aggregation of learning objects taking into account the pedagogical context for their use (Saliah-Hassane, 2012). This standard establish the relationship between all the components (Software, hardware and learning systems) in order to ease the design and implementation of pedagogically driven remote laboratory experiments (Saliah-Hassane, 2012). The smart learning environments are built on-the-fly, by learning actors, using social media, social networks, cloud computing tools and Internet of Things. A study indicated that the growth of remote laboratories could lead to a larger number of online engineering Baccalaureate degrees (Ibrahim and Morsi, 2005). The open education standard will need to undergo a similar rigor of standards proposed by organizations such as ASEE or IEEE.

Ideally, the organization(s) leading the open education standards should have institutional backing involving professional staff, or build on communities of practitioners and rely on their voluntary work. Repositories can be organized as places to share and exchange resources, which means that people are either users or producers, promoting the collaborative production of common resources (Hylen, 2007).

\section{International Challenges}

As MOOCs have the ability to serve an unlimited number of students across the globe, there are many international challenges ahead that need to be addressed in order for education to be truly global. In the meantime, higher education is facing a number of challenges: globalization, growing competition between higher 
educational institutions, and rapid technological development. MOOC is one of these challenges, but may also be a sound strategy for individual institutions to meet them.

The landscape is suddenly alive with new educational technologies that are making it possible for a great many more individuals to learn high-level skills and content at a minimal price, but these technologies may ultimately challenge the very existence of the current residential campus model. The world needs educate more students because we need them to help solve the challenges the world is facing, and because education is the most powerful social and economic equalizer (Reif, 2012). The highest ambition of an advanced society to significantly lower the barriers of access to education, thus universities such as MIT are creatively exploiting the power of these new technologies to make education more affordable, more accessible and more effective (Reif, 2012).

Opening up MOOCs to the world means that the courses will need to integrate multi-cultural, multidimensional, multi-faceted, and international features in their content. Although most resources are currently produced in developed countries, MOOCs are a global development, and can foster international co-operation between institutions as well as peer-to-peer collaboration. Although the main language so far is English, translation of resources combined with a growing number of non-English projects cater for greater language diversity and increased global use (Hylen, 2007). The potential number of users can be enormous.

Many of the MOOCs like Khan Academy are translating their courses to different languages. However, it is not enough to just translate the text transcripts. Ideally, the audio and video should also be adapted to the international audience, with new technologies required for the seamless integration of the two. In addition to translation of languages, work must also be done in translating other aspects of the course, such as cultural references and examples, idioms, measurement units, etc.

\section{Future Implications}

MOOCs are just the first step for the future in education. In the future, the concept of the classroom will adapt to various learning environments and content. The classroom of the future will contain a blend of real and virtual instructors, and students may be located in different parts of the world. The classroom environment can be instantly transformed from a traditional class to external virtual environments such as laboratories, museums, zoos, etc. The pace of the course is no longer dictated by the instructor or the levels of the classmates, but each individual student. Schools will be defined by their own content that teachers create from open course repositories. A curriculum can be custom designed based on the students' interests and abilities together with the requirement of the schools. There will be instant access to students' progress through many levels of assessments and automatic feedback for improvement. 
A first step in the integration of course content can start with audio clips of online course objects, such as integrating courses from Coursera, Khan Academy, and Udacity clips into custom voices and languages. Instructors can then integrate audio content from multiple courses into a custom course for their educational institute. The next step involves video integration, in which video content can be integrated across multiple sources, creating a consistent learning platform. Gamification will occur in which current gaming technologies will spearhead the education development of the future. For example, future educational videos may not be much different than current gaming platforms with choices of favorite educational avatars.

Next, future content integration in which a "mashup" of education content in the form of video, audio, text, and graphics across different sources will transpire. Social networks and crowdsourcing will play a vital role to garner instant feedback and to help control the quality of educational content by correcting mistakes. Computational social models will emerge as the platform for the inclusion of social knowledge for data analysis (Santos, 2012). The future will merge social networking and learning content to create a personalized blend of real-time education experience for the next generation of learners.

Automation will be critical in the future customization of courses where timing is flexible, and bots will be deployed to custom program courses in course delivery, forums, and deadlines. Courses can be taken independent of time, where students can proceed at their own pace, with automatic programs used for monitoring, assessment, and communication.

The future 3D virtual online classrooms will have instructors peering over the shoulder of students and transporting them to other environments. There will be a mix of real and virtual students in the classroom and even virtual intelligent instructors who are ideal combinations of optimal instructors. Educational institutions should help define the frontier for the future in education by taking advantage of the opportunities and charting the path towards truly global education.

\section{Conclusions}

We are in the dawn of the turning point in education, as MOOCs, fast broadband connections, and new technologies come together to define a new phase in education. In this new era of online education, institutions should focus on creating global insights into how technologies can serve both our own universities and educational institutions everywhere. This paper reviews the platforms and technologies currently available for online engineering education, provides guidelines for combining MOOCs with live university courses, summarizes the requirements for open standards in engineering education, describes the international challenges, and discusses the implications for future educators and students. Although new education technologies will change rapidly, existing universities and institutions can capitalize on their strengths that MOOCs cannot offer, such as instant feedback, live interaction, individual attention, and 
impromptu assessments. Long-term viability for universities will be dictated by the value and cost to students, type of academic credit received, and value of that academic credit to potential employers. Educators can thus manage the vast educational content to pave the way for integration of MOOCs in the future virtual classrooms.

\section{References}

edX FAQ, https://www.edx.org/faq, 2013.

J.D.H. Gaffney, E. Richards, M. B. Kustusch, L. Ding, and R. J. Beichner, "Scaling Up Education Reform", Journal of College Science Teaching, pp. 18-23, 2008.

L. Hardesty, "Is MIT Giving Away the Farm? The surprising logic of MIT's free online education program", MIT Technology Review, August 21, 2012

J. Hylen, "Giving Knowledge for Free: The Emergence of Open Educational Resources", OECD Centre for Educational Research and Innovation (CERI), 2007.

W. Ibrahim and R. Morsi, "Online Engineering Education: A Comprehensive Review", Proceedings of the 2005 American Society for Engineering Education Annual Conference \& Exposition, 2005

S. Jaschik, "MOOCs, Reputation and Credit Ratings", Inside Higher Ed., Sep. 2012.

L. Kinney and M. Liu, "Faculty and Student Perceptions of Online Learning in Engineering Education", Proceedings of the 2012 American Society for Engineering Education Annual Conference \& Exposition, 2012.

D. Koller, "Death Knell for the Lecture: Technology as a Passport to Personalized Education", The New York Times, Dec. 5, 2011.

S. Kolowich, "Coursera doubles university partnerships", Inside Higher Ed., Sep. 2012.

T. Lewin, "Education Site Expands Slate of Universities and Courses", The New York Times,Sep. 19, 2012a.

T. Lewin, "Instruction for Masses Knocks Down Campus Walls", The New York Times, Mar. 4, $2012 \mathrm{~b}$.

F. G. Martin, "Will Massive Open Online Courses Change How We Teach? ", Communications of the ACM, vol. 55, no. 8, pp. 26-28, Aug. 2012.

A. McAuley, B. Stewart, G. Siemens, and D. Cormier, "The MOOC Model for Digital Practice", 2010.

L. Pappano, The Year of the MOOC, The New York Times, Nov. 12, 2012.

R. Reif, "MIT Inauguration Speech", 2012. 
M. Riojas, S. Lysecky, and J. Rozenblit, "Educational Technologies for Precollege Engineering Education", IEEE Transactions on Learning

Technologies, vol. 5, no. 1, 2012.

H. Saliah-Hassane, "Standard for Networked Smart Learning for Online Laboratories", IEEE Draft Development Overview, 2012.

E.E. Santos, "Computational Social Systems", Proceedings of the IEEE, vol. 100, pp. 1271-1272, 2012.

J. M. Tabas, C. M. LeMay, and E. Freije, "Online Education: The End of Learning", Proceedings of the 2012 American Society for Engineering Education Annual Conference \& Exposition, 2012.

F.S. Tsai, K. Natarajan, S. D. Ahipasaoglu, C. Yuen, H. Lee, N.-M. Cheung, J. Ruths, S. Huang, and T. L. Magnanti, "From Boxes to Bees: Active Learning in Freshmen Calculus", IEEE Annual Global Engineering Education Conference (EDUCON), 2013.

F.S. Tsai, C. Yuen, and N.-M. Cheung, "Interactive Learning in Pre-University Mathematics", IEEE International Conference on Teaching, Assessment and Learning for Engineering, 2012. 